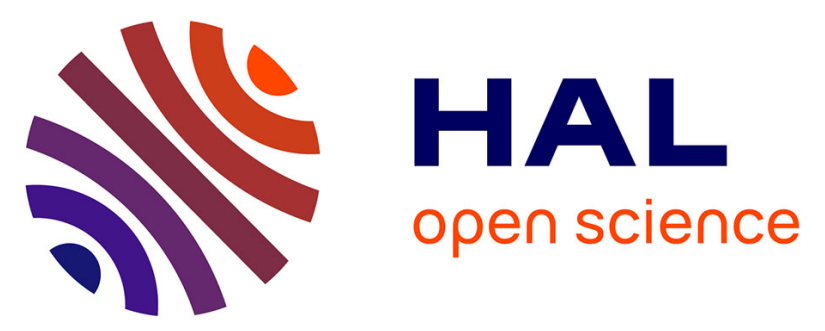

\title{
Design and Characterisation of VO 2 Based Switches for Ultra-Fast Reconfigurable Devices
}

\author{
Mohammad Nikhian Sadiq, Marc Le Roy, André Pérennec, Paul Laurent, \\ Noham Martin, Damien Passerieux, Aurelian Crunteanu, Rémi Boyer, \\ Frédéric Dumas-Bouchiat, Marie-Blandine Martin, et al.
}

\section{To cite this version:}

Mohammad Nikhian Sadiq, Marc Le Roy, André Pérennec, Paul Laurent, Noham Martin, et al.. Design and Characterisation of VO 2 Based Switches for Ultra-Fast Reconfigurable Devices. International Microwave Workshop Series on Advanced Materials and Processes (IMWS-AMP 2019), Jul 2019, Bochum, Germany. hal-02135908

\section{HAL Id: hal-02135908 \\ https://hal.univ-brest.fr/hal-02135908}

Submitted on 21 May 2019

HAL is a multi-disciplinary open access archive for the deposit and dissemination of scientific research documents, whether they are published or not. The documents may come from teaching and research institutions in France or abroad, or from public or private research centers.
L'archive ouverte pluridisciplinaire HAL, est destinée au dépôt et à la diffusion de documents scientifiques de niveau recherche, publiés ou non, émanant des établissements d'enseignement et de recherche français ou étrangers, des laboratoires publics ou privés. 


\title{
Design and Characterisation of $\mathrm{VO}_{2}$ Based Switches for Ultra-Fast Reconfigurable Devices
}

\author{
M. N. Sadiq ${ }^{1}$, M. Le Roy ${ }^{1}$, A. Perennec ${ }^{1}$, P. Laurent ${ }^{1}$, N. Martin ${ }^{1}$, D. Passerieux ${ }^{2}$, A. Crunteanu ${ }^{2}$, \\ R. Boyer ${ }^{3}$, F. Dumas-Bouchiat ${ }^{3}$, M-B. Martin ${ }^{4}$, L. Divay ${ }^{4}$, Q. Levesque ${ }^{4}$, G. Tanné $^{1}$ \\ ${ }^{1}$ Univ Brest, Lab-STICC, UMR 6285, CNRS, F-29200, Brest, France \\ ${ }^{2}$ Univ Limoges, XLIM, UMR 7252, CNRS, F-87060, Limoges, France \\ ${ }^{3}$ Univ Limoges, IRCER, UMR 7315, CNRS, F-87060, Limoges, France \\ ${ }^{4}$ Thales Research \& Technology, Palaiseau, France \\ \{Mohammad-Nikhian.Sadiq, Marc.LeRoy, Gerard.Tanne\}@univ-brest.fr
}

\begin{abstract}
Mott transition materials seem particularly promising to design reconfigurable devices. In this paper, Vanadium Dioxide $\left(\mathrm{VO}_{2}\right)$ is studied and characterized to design switches and elementary RF devices. The study shows experimentally promising $R F$ performances under electrical control and also for an optical excitation of the $\mathrm{VO}_{2}$ with ultrashort switching time. These results put forward the use of $\mathrm{VO}_{2}$ switches as a core function to design ultra-fast purpose RF devices dedicated to future military and civilian standards.

Keywords - Vanadium dioxide, ultra-fast switches, reconfigurable architectures, frequency shift keying.
\end{abstract}

\section{INTRODUCTION}

The new military and civilian standards (e.g. massive MIMO and 5G Network purpose beamforming) and the allocation of the new frequency bands had increased the needs of reconfigurable and agile radiofrequency (RF) devices. In these circumstances, the switching speed of the RF devices is an essential and crucial parameter. Actual devices are, for the most part, based on mechanical technologies like the Micro-Electro-Mechanical Switches (MEMS) or are based on semiconductors components like PIN Diodes, varactors or Field Effect Transistors (FET) [1]. The latter are compact and exhibit a switching time in the range of $50 \mathrm{~ns}$ down to $1 \mathrm{~ns}$, but are less interesting over wide band applications where non-linear parasitic effects are hard to take into account. On the other hand, MEMS switching time ranges typically between $500 \mu \mathrm{s}$ down to $1 \mu \mathrm{s}$ [1]. In that context, the Vanadium Dioxide $\left(\mathrm{VO}_{2}\right)$, which is a phase switching ultrawide band material [2], has been identified as a promising solution with a switching time in the range of $0.1 \mu \mathrm{s}$ down to 100 ps [1].

This study focuses on the design of elementary agile RF devices using $\mathrm{VO}_{2}$ based switches. The RF performances are experimentally characterized under an electrical control and the very low switching time using an optical excitation. The design and complete characterization of these devices are essential to have a set of reliable elementary blocks in order to build more advanced functions (SP2T, SP4T, switched-line phase shifters ...).

\section{VANADIUM DiOXIDE $\mathrm{VO}_{2}$ : PROPERTIES AND ACTIVATIONS}

The Vanadium Dioxide $\left(\mathrm{VO}_{2}\right)$ is a Metal-Insulator Transition (MIT) material also known as the Mott
Transition [3]-[4]. When increasing the temperature from ambient temperature, the $\mathrm{VO}_{2}$ is in its semiconductor state (insulator) until the insulator $\rightarrow$ metal transition temperature $\left(\mathrm{T}_{\mathrm{cm}}=68^{\circ} \mathrm{C}\right)$, and becomes conductor above. Decreasing temperature, this reversible transition (metal $\rightarrow$ insulator) occurs at a slightly lower temperature $\left(\mathrm{T}_{\mathrm{ci}}=65^{\circ} \mathrm{C}<\mathrm{T}_{\mathrm{cm}}\right)$ due to a well-known hysteresis properties. $\mathrm{T}_{\mathrm{cm}}, \mathrm{T}_{\mathrm{ci}}$ and electrical resistivity can be adjusted according to material properties.

The $\mathrm{VO}_{2}$ transition can be obtained either with a thermal [5], an optical [6] or an electrical [7] command.

The thermal command has the disadvantage of being too slow due to the classical thermal inertia needed to heat up and especially to cool down the $\mathrm{VO}_{2}$. Conversely, the electrical and optical commands are much faster (potentially under $1 \mathrm{ps}$ for the optical command) [8] and therefore particularly relevant for the foreseen RF applications.

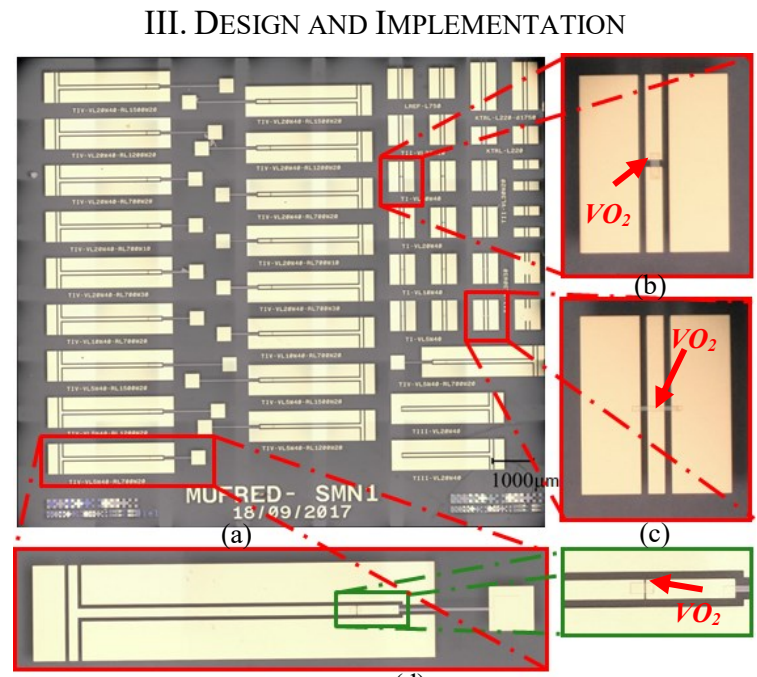

(d)

Fig. 1. (a) Photo of the wafer with the devices, (b) series switch, (c) shunt switch and (d) frequency tunable stub based on $\mathrm{VO}_{2}$.

Several devices are studied in this article (Fig. 1(a)). Firstly, Coplanar Waveguide (CPW) switches are designed in series (Fig. 1(b), i.e. $\mathrm{VO}_{2}$ thin film between input and output RF ports) and shunt (Fig. 1(c) with $\mathrm{VO}_{2}$ between ground and hot lines of CPW) configurations. 


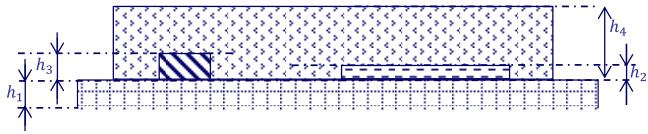

\begin{tabular}{|c|c|c|c|c|}
\hline Layer & $\begin{array}{l:lll}\vdots & \vdots & \vdots & \vdots \\
\end{array}$ & ------ & & 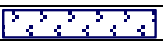 \\
\hline Material & R-cut Sapphire & Molybdene & $\mathrm{VO}_{2}$ & Gold $\mathrm{Au}$ \\
\hline Thickness & $\mathrm{h}_{1}=508 \mu \mathrm{m}$ & $\mathrm{h}_{2}=150 \mathrm{~nm}$ & $\mathrm{~h}_{3}=200 \mathrm{~nm}$ & $\mathrm{~h}_{4}=1.5 \mu \mathrm{m}$ \\
\hline Process & & Lift-off & PLD & Lift-off \\
\hline Lab & & XLIM & IRCER & XLIM \\
\hline
\end{tabular}

Fig. 2. Cross-section (not to scale) of the different layer implementation.

Those devices are implemented with different sizes $\left(\mathrm{VO}_{2}\right.$ gap length between $5 \mu \mathrm{s}$ to $30 \mu \mathrm{s}$ ) to enhance the understanding and the characterization of the material properties and the impact on RF performances.

In a complementary approach, $\mathrm{VO}_{2}$ material has also been integrated into a set of simple RF devices to make them agile. Several stub configurations have been designed: an open circuit one is detailed below (Fig. 1(d)). It consists of a $\mathrm{VO}_{2}$ based switch in series configuration in order to increase the length of the stub and consequently shift the resonance frequency toward the low frequency, i.e. a shift from $15 \mathrm{GHz}$ to $13 \mathrm{GHz}$.

In that case, a Molybdene biasing line has been added and optimized to control $\mathrm{VO}_{2}$ state through an electrical command without degrading the RF performances.

The main process of devices implementations are illustrated in Fig. 2 together with the material characteristics. Moreover, four probes measurements showed a $\mathrm{R}_{\mathrm{OFF}} / \mathrm{R}_{\mathrm{ON}}$ ratio of $2.5 \times 10^{4}$ after $\mathrm{VO}_{2}$ deposition on Sapphire using PLD.

\section{RF RESULTS}

The first measurements have been conducted at LabSTICC using a $200 \mu \mathrm{m}$ GSG pitched probe station and under voltage command applied between both ends of the $\mathrm{VO}_{2}$ material. Only, the results of most relevant devices (series switches and frequency tunable stubs) for our final applications are shown here for brevity.

\section{A. Series Switches Specifications}

The evolutions of the $S_{11}$ and $S_{21}$ parameters of the $5 \mu \mathrm{m}$ $\mathrm{VO}_{2}$ gap based series switch are given in Fig. 3(a). In their insulator states (OFF state), all the $\mathrm{VO}_{2}$ based switches understudied (gap of $5 \mu \mathrm{m}, 10 \mu \mathrm{m}, 20 \mu \mathrm{m}$ and $30 \mu \mathrm{m}$ ) show good isolation level $\mathrm{S}_{21} \leq-20 \mathrm{~dB}$ in the $8-18 \mathrm{GHz}$ frequency band. In its metallic state (ON state), the $\mathrm{VO}_{2}$ introduces variable losses with the gap length, i.e. $\mathrm{VO}_{2}$ length. Those losses are consistent with $\mathrm{VO}_{2}$ switch state-of-the-art, i.e. within $-1.2 \mathrm{~dB}$ to $-2.0 \mathrm{~dB}$ respectively for a gap varying from $5 \mu \mathrm{m}$ to $30 \mu \mathrm{m}$, and with $\mathrm{S}_{11} \leq-14 \mathrm{~dB}$ over $8-20 \mathrm{GHz}$ frequency band.

Like the resistivity versus temperature curve, I-V curve displays a hysteresis (Fig. 3(b)) with two different commutation voltages: insulator, $\mathrm{V}_{\mathrm{ci}}$, and metallic, $\mathrm{V}_{\mathrm{cm}}$. The voltage pair $\left(\mathrm{V}_{\mathrm{ci}}, \mathrm{V}_{\mathrm{cm}}\right)$ is directly proportional to the length of the $\mathrm{VO}_{2}$ gap: $(5.2 \mathrm{~V}, 9.6 \mathrm{~V})$ and $(7.9 \mathrm{~V}, 20.2 \mathrm{~V})$ respectively for a $5 \mu \mathrm{m}$ and a $30 \mu \mathrm{m}$ gap. Hence a higher voltage is needed to obtain the same current while increasing the $\mathrm{VO}_{2}$ length (i.e. the corresponding resistance).

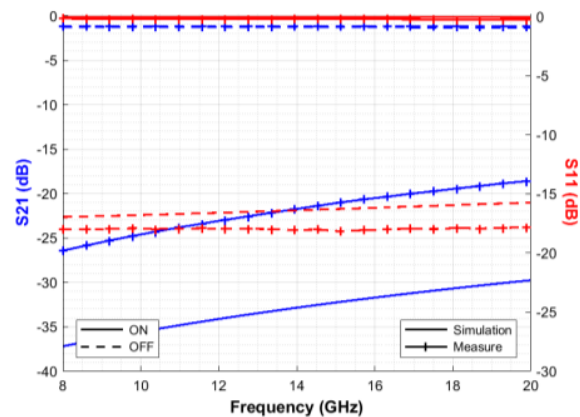

(a)

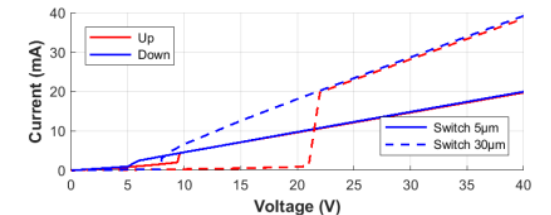

(b)

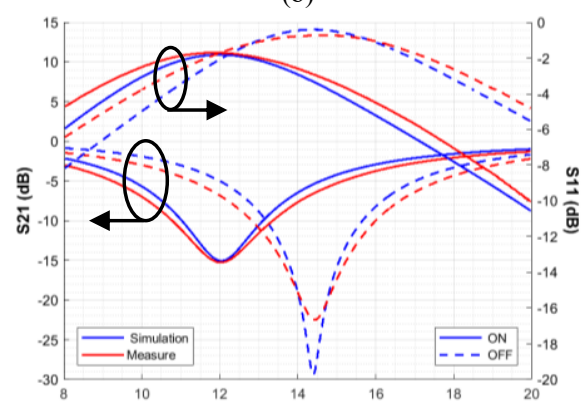

(c)

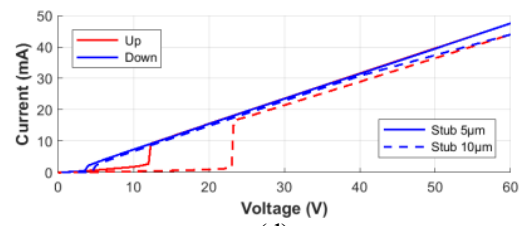

(d)

Fig. 3. (a) S-parameters of the $5 \mu \mathrm{m} \mathrm{VO}_{2}$ gap series switch, (b) I-V characteristic curve of the $5 \mu \mathrm{m}$ and $30 \mu \mathrm{m} \mathrm{VO}_{2}$ gap series switch (in series with a $2 \mathrm{k} \Omega$ resistor), (c) S-parameters of the $5 \mu \mathrm{m} \mathrm{VO}_{2}$ gap stub, (d) I-V characteristic curve of the $5 \mu \mathrm{m}$ and $10 \mu \mathrm{m} \mathrm{VO}_{2}$ gap stub (with a $1.3 \mathrm{k} \Omega$ resistive line).

At this stage on this wafer, $5 \mu \mathrm{m}$ series switches seem to provide the best trade-off between isolation in OFF state, transmission losses in $\mathrm{ON}$ state and required switching power.

\section{B. Stubs Specifications}

To control the commutation of the $\mathrm{VO}_{2}$ when integrated into the frequency tunable stub, an additional DC probe has been used and placed over the biasing pad (Fig. 1(d)).

$\mathrm{S}_{11}$ and $\mathrm{S}_{21}$ parameters curves versus frequency are given are given for both states in Fig. 3(c) $\left(\mathrm{VO}_{2}\right.$ gap of $\left.5 \mu \mathrm{m}\right)$. A slight shift in the resonance frequency has been noticed toward the low frequency $(14.4 \mathrm{GHz}$ instead of $15 \mathrm{GHz})$ in the insulator state of the $\mathrm{VO}_{2}$, primarily explained by the R-cut Sapphire anisotropic permittivity. The frequency shift occurred by switching the $\mathrm{VO}_{2}$ in its metallic state is also slightly higher than expected $(2.4 \mathrm{GHz}$ instead of $2 \mathrm{GHz})$ and can be mainly explained by the lower value of the resistive line's resistivity than used in the simulation. In both state, 
good isolation parameters $\mathrm{S}_{21}<-15 \mathrm{~dB}$ are obtained at both work frequencies

A retro-simulation has allowed to obtain the effective permittivity of the R-cut Sapphire $\left(\varepsilon_{\mathrm{r}}=10.6\right)$ and Molybdene's resistivity $\left(5.7 \times 10^{-6} \Omega . \mathrm{m}\right)$.

The measured characteristic curves $\mathrm{I}-\mathrm{V}$ are given in Fig. 3(d) for stubs with $5 \mu \mathrm{m}$ and $10 \mu \mathrm{m} \mathrm{VO}_{2}$ gap. Voltage pairs $(3.7 \mathrm{~V}, 12.3 \mathrm{~V})$ and $(4.8 \mathrm{~V}, 23.3 \mathrm{~V})$ respectively for $5 \mu \mathrm{m}$ and $10 \mu \mathrm{m}$ gaps are noticed. Once more, $5 \mu \mathrm{m} \mathrm{VO}_{2}$ gap provides the more relevant trade-off.

\section{SWitching Time AND Optical COMMAND}

Experimentations based on an optical command have also been conducted on $10 \mu \mathrm{m}$ series switches at Thales Research \& Technology (TRT) on the same wafer by using a three wavelength laser (UV $355 \mathrm{~nm}, \mathrm{G} 532 \mathrm{~nm}$ and NIR $1064 \mathrm{~nm}$ ) with a 4 ns long pulse placed over a probe station with three optical lenses $(\times 2, \times 10$ and $\times 50)$.

First, increasing the power of the excitation leads to a longer time in the metallic state (Fig. 4(a)) corresponding to the time the material needs to dissipate the additional energy provided by the laser. A deeper insight into the voltage at the $\mathrm{VO}_{2}$ 's terminals shows a step during the rising slope (Fig. 4(b)). The first slope corresponds to a fast reaction of the material but with an insufficient level of energy to maintain a long-lived conductivity. And the second one corresponds to a slower reaction where the energy is sufficient enough to reach conductivity as explained in [9].

Boltzmann sigmoid equation (1) has been used to estimate the rising time, where $a$ and $b$ are respectively the low and high horizontal asymptotes, $\tau$ the time constant and $t_{0}$ the central value.

$$
f(t)=b+\frac{a-b}{1+e^{\frac{t-t_{0}}{\tau}}}
$$

$\left(\mathrm{Model}_{1}\right)$ considers only the fast reaction and estimates a $4.4 \mathrm{~ns}$ rising time whereas $\left(\mathrm{Model}_{2}\right)$ approximates both reactions and estimates a 33 ns rising time. Finally, a more complete model $\left(\mathrm{Model}_{3}\right)$, taking into account the response disruption in the reaction provides a $40.1 \mathrm{~ns}$ rising time. This approach is of prime interest to identify the different phenomena that rule of the switching time and to quantify the latter in a real RF switch implementation. From these results, complementary studies are being conducted in order to decrease the switching time.

Moreover, the $\mathrm{VO}_{2}$ based series switches are observed under a microscope: before any optical excitation, the $\mathrm{VO}_{2}$ appears blue (Fig. 4(c)). After several excitations using the NIR wavelength, degradations are visible (Fig. 4(d)) and electrical parameters change irreversibly (Fig. 4(a)). This phenomenon might be explained by a partial ablation of the material by the laser excitation.

\section{CONCLUSION}

Promising results are shown about RF specifications and rising time of the $\mathrm{VO}_{2}$ to be used in the design of RF devices for ultra-fast reconfigurable applications.

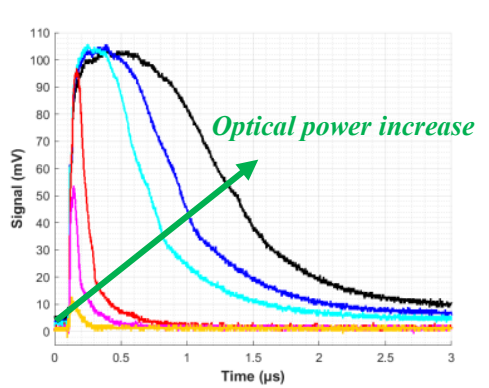

(a)

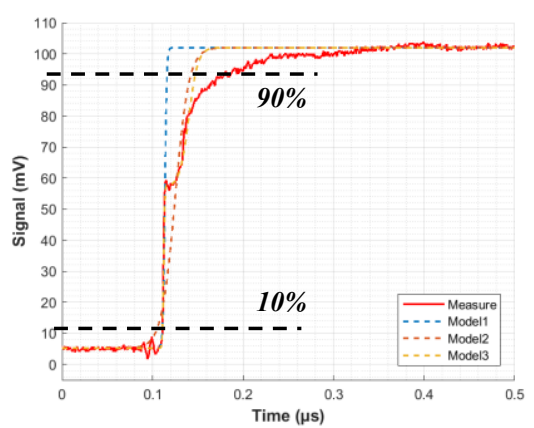

(b)

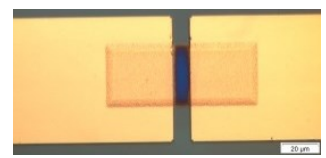

(c)

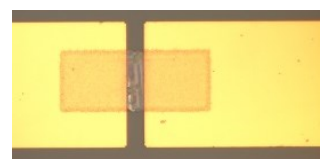

(d)
Fig. 4. (a) Voltage at the $\mathrm{VO}_{2}$ switches outputs while increasing NIR optica power and (b) model estimation of the switching time (10-90\% rising time) with NIR wavelength, (c) Picture of the $10 \mu \mathrm{m}$ gap $\mathrm{VO}_{2}$ series switch before NIR optical excitation, (d) and after several NIR optical excitations.

Thanks to these experimental validations, $\mathrm{VO}_{2}$ switches implementation and optical control are currently under improvement to design ultra-fast SP2T and SP4T optically controlled microwave switches dedicated to advanced functions such as 2 and 3-bits phase shifters.

\section{ACKNOWLEDGMENT}

The authors would like to thank the French National Research Agency (ANR) for the MUFRED project funding and C. Prevot and B. Servet from TRT for optical experiments.

\section{REFERENCES}

[1] G. M. Rebeiz, RF MEMS: Theory, Design and Technology, Hoboken, New Jersey: Wiley-Interscience, 2003.

[2] A. Hariri, et al., "Very Wide-Band and Compact $\mathrm{VO}_{2}$ Based Switches", IEEE MTT-S IMWS-AMP 2018, Ann Arbor, MI, USA, 2018.

[3] N. F. Mott, "Metal-Insulator Transition," Reviews of Modern Physics, vol. $40, \mathrm{n}^{\circ} 14,1968$.

[4] G. Stefanovich, et al., "Electrical Switching and Mott Transition in $\mathrm{VO}_{2}$," Journal. Phys.: Condes. Matter, vol. 12, pp. 8837-8845, 2000.

[5] T. Ben-Messaoud, et al., "High Contrast Optical Switching in Vanadium Dioxide Thin Films," Optics Communications, vol. 281, pp. 6024-6027, 2008.

[6] A. Crunteanu, et al., "Microwave Switching Functions using Reversible Metal-Insulator Transition (MIT) in $\mathrm{VO}_{2}$ Thin Films," 2007 European Microwave Conference, 2007.

[7] A. Mennai, et al., "High Cut-off Frequency RF Switches Integrating a Metal-Insulator Transition Material," IEEE MTT-S, IMS 2015, Phoenix, AZ, USA, 2015.

[8] A. Cavalleri, et al., "Femtosecond Structural Dynamics in $\mathrm{VO}_{2}$ During an UltraFast Solid-Solid Phase Transition," Physical Review Letters, vol. $87, \mathrm{n}^{\circ} 123,2001$

[9] T. L. Cocker, et al., "Phase Diagram of the UltraFast Photoinduced Insulator-Metal Transition in Vanadium Dioxide," Physical Review B. 85, vol. 85, pp 155120(11), 2012. 